\title{
REFLEXÕES METAORTOGRÁFICAS ÀS MARGENS DO ROMANCE “A MAIS ENCANTADORA MULHER” (1903), DE GONZAGA FILHO
}

\section{METAORTHOGRAPHIC REFLECTIONS ON THE EDGE OF THE NOVEL “A MAIS ENCANTADORA MULHER” (1903), BY GONZAGA FILHO}

Maria Hozanete Alves de Lima ${ }^{1}$ Felipe Morais de $\mathrm{Melo}^{2}$

\section{RESUMO}

No ano de 1903, José Basileu Neves Gonzaga Filho (02/12/1849 - 09/09/1931) publica o romance $A$ mais encantadora mulher - um romance para senhoras. À época, a escrita das palavras era marcada por variações gráficas, de modo que poderíamos encontrar, por exemplo, no mesmo texto, os pares "charta/carta", "mez/mes" e "asa/aza". Ressentia-se o romancista de não haver um discurso comum para a grafia dos termos da língua. Assim, ao escrever seu romance, Gonzaga Filho elabora um pequeno léxicon para justificar a escrita de um conjunto de vocábulos. Este trabalho segue um percurso metodológico de natureza bibliográfica e documental, está orientado pelos pressupostos teóricos de estudos grafemáticos desenvolvidos por alguns historiadores da língua do mundo hispânico (SÁNCHEZPRIETO BORJA, 1998; PENSADO, 1998; FRAGO GRACIA, 2002; RAMÍREZ LUENGO, 2012) e objetiva refletir sobre algumas motivações elencadas por Gonzaga Filho (1903) para justificar suas soluções gráficas, sejam elas fonéticas, etimológicas, prosódicas ou de harmonia (neolatina). Encontramos em Gonzaga Filho uma postura metaortográfica que se insere no seio da história da ortografia da língua portuguesa e que revela o percurso que a escrita da língua portuguesa foi tomando, em sincronias passadas, rumo à sua estandardização.

PALAVRAS-CHAVE: Linguística Histórica; história da ortografia portuguesa; variação gráfica; Gonzaga Filho.

\begin{abstract}
In 1903, José Basileu Neves Gonzaga Filho (Dec. 02, 1849 - Sep. 09, 1931) published the novel $A$ mais encantadora mulher - um romance para senhoras (The most charming woman - a novel for ladies). At that time, the spelling of the words was marked by graphic variations, so that we could find, for example, in the same text, the pairs "charta / carta", "mez / mes" and "asa / aza". The novelist resented that there was no common ground on the spelling of the terms of language. Thus, when writing his novel, Gonzaga Filho elaborates a small lexicon to justify the writing of a set of words. This work follows a methodological path of bibliographical and documentary nature, guided by the theoretical assumptions taken from the graphematic studies developed by some Spanish historians of language (SÁNCHEZPRIETO BORJA, 1998; PENSADO, 1998; FRAGO GRACIA, 2002; RAMÍREZ LUENGO, 2012) and aims to ponder about some motivations listed by Gonzaga Filho in

\footnotetext{
1 Professora do Departamento de Letras e do Programa de Pós-Graduação em Ensino da Linguagem, da Universidade Federal do Rio Grande do Norte, Brasil. Pós-doutora em Linguística pelo Institut des Textes et Manuscrits Modernes (ITEM/ENS/CNRS), França. E-mail: hozanetelima@gmail.com

2 Professor do Instituto Federal de Educação, Ciência e Tecnologia do Rio Grande do Norte (IFRN), Brasil. Doutor em Linguística pela Universidade Federal do Rio Grande do Norte, com 1 ano de estágio doutoral na Universidad Autónoma de Querétaro (UAQ), México. E-mail: felipe_morais@yahoo.com.br
} 
order to justify his spelling solutions, whether they are phonetic, etymological, prosodic or of (neo-Latin) harmony. We find in Gonzaga Filho a metaorthographic attitude that is inserted in the heart of the history of Portuguese orthography and that reveals the pathway that the writing of the Portuguese language has taken, in past synchronies, towards its standardization.

KEYWORDS: Historical Linguistics; history of Portuguese orthography; graphical variation; Gonzaga Filho.

\section{INTRODUÇÃO}

Embora haja nos últimos 20 anos algumas publicações no Brasil incontornáveis para quem se interessa pelo estudo da (orto)grafia ${ }^{3}$, a exemplo de Massini-Cagliari e Cagliari (2001) e Silva (2015) ${ }^{4}$, não há muitas obras que tenham se dedicado aos usos gráficos no português brasileiro em perspectiva diacrônica, sobretudo se buscarmos pesquisas não focadas nas relações entre escrita e oralidade. O estudo dos usos gráficos parece não se destacar na agenda da Linguística Histórica nacional. Nesse sentido, Morais de Melo (2018, p. 654-682) traz um painel de trabalhos dedicados a esse nível de análise (artigos, dissertações e teses) e indica - pois, malgrado não seja o Programa Para a História do Português Brasileiro (PHPB) a única diretriz que pauta os estudos diacrônicos brasileiros, é inegável, histórica e atualmente, a importância desse projeto para as investigações da área - a quase ausência de trabalhos de cunho grafemático (os existentes estão todos relacionados à fonética e fonologia) nos mais de 10 volumes da série de livros Para a história do português brasileiro, que vai de 1998 a 2010 (cf. MORAIS DE MELO, 2018, p. 54). A nova série (obra de referência fruto das décadas de empreendimento sério e de fôlego da equipe nacional e das equipes regionais), História do português brasileiro, que conta com 10 volumes (tendo sido o último publicado neste ano de 2021), refletindo naturalmente os programas previamente delineados, não altera esse espaço secundário legado à Grafemática ${ }^{5}$.

Já repetido - quer como adjetivo, quer como substantivo - no parágrafo anterior, cabe um esclarecimento sobre o termo Grafemática. Ele foi tomado do título do livro Estudios de Grafemática en el dominio hispánico (BLECUA; GUTIÉRREZ; SALA, 1998) e é entendido neste artigo como o estudo dos signos escritos considerados pelo prisma

\footnotetext{
3 Ao longo de todo este trabalho, podem surgir tanto o registro "ortografia" quanto "(orto)grafia": o primeiro será empregado nas acepções mais tradicionais ou quando fizermos referência à perspectiva sincrônica, isto é, à escrita atual normatizada do português; o segundo, sempre que quisermos salientar o peculiar estado de variação de que a escrita gozou no eixo diacrônico, ou seja, ao longo de muitos séculos, quando não havia - ao menos no sentido que se lhe atribui atualmente - um padrão ortográfico, mas formas diversas, tradicionais a seu modo (algumas mais frequentes, outras menos produtivas), que conviviam na escrita corrente da época. A percepção dessas vicissitudes refletida na nomenclatura semiparentética encontramo-la, por exemplo, em Morreale (1998), Ramírez Luengo (2015) e, na linha desses e de outros autores que se dedicaram à Grafemática no domínio hispânico, Morais de Melo (2018).

4 A despeito de serem obras produzidas no além-mar por investigadores de outros países, é preciso, nesta vertente historiográfica, mencionar - pela dimensão e profundidade de suas abordagens - os estudos de Kemmler (2001) e Gonçalves (2003).

5 Afora todos os artigos do volume 3 (HORA; BATTISTI; MONARETTO, 2019), que necessariamente dialogam mui amiúde com pautas (orto)gráficas, os dois estudos - considerando os 10 volumes - que abordam mais detidamente o que consideramos Grafemática (definida à continuação no corpo do texto) são Barbosa e Lima (2019) e Telles (2019). Telles, aliás, levou a cabo uma série de pesquisas nessa área (TELLES, 2005, 2008; TELLES; SOUZA, 2017), geralmente relacionadas a textos medievais e/ou à relação da escrita com a fonologia do português.
} 
linguístico (cf. CATACH, 1989, P. 334) ${ }^{6}$, cujos objetos de estudo são, segundo Contreras (1994, p. 139, tradução nossa) ${ }^{7}$,

1. Unidades grafemáticas. Grafema (segmental, suprassegmental, adsegmental), alógrafo e arquigrafema.

2. Estrutura grafemática.

3. Oposições grafemáticas. Classes.

4. Frequência grafemática.

5. Função dos grafemas: a) relações sintagmáticas: compatibilidades e incompatibilidades grafemáticas; b) relações paradigmáticas: correspondências grafemáticas.

E finalmente, e sem renunciar a uma concepção imanentista do grafema, um sexto tema, sem dúvida de interesse pela sua aplicação posterior à ortografia:

6. Correlações fonografemáticas e grafofonemáticas.

Esses são os programas de estudo que Contreras (1994, p. 139) traz para uma grafemática sincrônica. Podemos aplicá-lo perfeitamente ao corte diacrônico, e teríamos o que Elizaicín, Malcouri e Coll (1998) chamam de Grafemática Histórica. Ela, apesar de não exercer protagonismo na Linguística Histórica brasileira, conforme vimos acima, mantém-se viva ${ }^{8}$, especialmente pela grande demanda de textos antigos que necessitam vir à luz, trazendo consigo - para além de suas condições enunciativas e discursivas -, a história da língua em sua realização formal, revelando carizes de sincronias passadas cujos efeitos reverberam na contemporaneidade. Os textos de épocas pretéritas mantêm-se, nesse sentido, vivos, e traduzem, para nós, um percurso de lutas, um espaço para que compreendamos de que modo certos fenômenos linguísticos se comportavam ou de que maneira os utentes ou estudiosos se relacionavam com eles.

É nessa seara de interesse que se situa este estudo, centrado nas reflexões metaortográficas desenvolvidas em duas seções, Simples nota e Post-impressum, da obra A Mais encantadora mulher - um romance para senhoras, escrita há mais de 117 anos pelo irmão da famosa pianista e compositora brasileira Chiquinha Gonzaga, José Basileu Neves Gonzaga Filho $\left(2 / 12 / 1849\right.$ - 9/09/1931) ${ }^{9}$, doutor em medicina e bacharel em Letras. Há uma série de motivos que justificam a investigação desse material. A primeira diz respeito ao acesso que as notas nos dão a uma face do saber metalinguístico da virada do século XIX para o século XX. E a metalinguagem - máxime pela via da gramatização (cf. AUROUX, 2009) - é uma dimensão cara aos historiadores da língua. Como estamos nos valemos, neste momento, do peso que ao discurso metalinguístico dá Auroux (2009), é necessário fazer um esclarecimento: apesar de seu livro $A$ revolução tecnológica da gramatização, e alguns trabalhos que seguem suas premissas ${ }^{10}$, se preocupar com os fatos do sistema linguístico, colocando a discussão ortográfica explicitamente em segundo plano ${ }^{11}$, é perfeitamente adequado localizar o discurso metaortográfico no seio do discurso metalinguístico.

Embora não seja uma gramática ou um dicionário - destacadas como as duas tecnologias de base para o processo da gramatização (cf. AUROUX, 2009, p. 65) -, as notas metaortográficas de Gonzaga Filho não apenas importam por revelarem uma expressão do saber metalinguístico, mas também por estarem situadas num momento chave para a história

\footnotetext{
${ }^{6} \mathrm{O}$ termo usado por Catach (1989) é Graphémique.

${ }^{7}$ Contreras (1994) emprega a expressão Grafémica.

${ }^{8}$ Ver, por exemplo, Monte (2007), Assalim (2007), Toniolo (2007), Fachin (2011), Morais de Melo (2018).

9 Passaremos a tratar o autor por Gonzaga Filho e sua obra por A mais encantadora mulher.

${ }^{10}$ Vide, por exemplo, Guimarães (1996) e Pagotto (2001).

${ }^{11}$ Em segundo plano estão, vale sublinhar, as discussões (orto)gráficas, mas não a escrita como técnica, já que esta é tomada pelo pensador francês como ponto de inflexão do discurso metalinguísticos e, consequentemente, do processo de gramatização. A citações a seguir deixa clara essa distinção. Tratando da escrita como tecnologia revolucionária, ele afirma: "As discussões sobre a ortografia e os empreendimentos de reformas que pululam em todas as tradições mas diferentes época são de outra natureza” (AUROUX, 2009, p. 22).
} 
das ideias no Brasil: a fase de 1857 e 1939, que inaugura, consoante a periodização traçada por Guimarães (1996), os estudos sistemáticos sobre o português brasileiro. Conquanto Guimarães (1996), na linha de Auroux (2009), esteja pensando no sistema da língua, e não em questões (orto)gráficas, parece-nos correto afirmar que as inquietações metaortográficas do romancista participam desse cenário nacional de ebulição reflexiva em torno da língua.

A feição ortográfica, a propósito, reveste, no interior desse palco prolífico de ideias linguísticas, as notas em mira de outra valia peculiar. É ao longo da primeira metade do século XX que se operam, com mais afã, as ações com vistas ao estabelecimento de uma ortografia unificada, só conquistada efetivamente na segunda metade dessa centúria ${ }^{12}{ }^{13}$. Nessa esteira em que se vai gestando paulatinamente um estado de padronização ortográfica normativa de ampla difusão incidem, de acordo com Ramírez Luengo (2012, p. 169), três agentes decisivos (que o autor denomina de três polos de estandardização): as tradições gráficas herdadas do passado, a tarefa dos preceptores e educadores (este polo concerne aos textos metaortográficos) e os usos adotados pelo texto impresso ${ }^{14}$. A Simples nota e o Post-impressum, por esse ângulo, são dignos de atenção, pois, em adição às tradições herdadas, conjugam manifestamente elementos de dois dos três polos: trazem conteúdo metaortográfico (lembremo-nos, conforme já anunciado acima, que Gonzaga Filho era bacharel em Letras) para ser aplicado imediatamente (as duas notas figuram às margens do romance, a primeira antes e a segunda após o miolo ficcional) em seu $A$ mais encantadora mulher, configurando-se, portanto, em usos gráficos adotados pelo texto impresso. No tocante a esse último aspecto, o próprio Auroux (2009, p. 56) salienta o papel pungentemente efetivo da imprensa para a normalização ortográfica:

A prática manuscrita medieval deixa teoricamente espaço, em cada exemplar, para a variabilidade, sobretudo ortográfica. Com a imprensa, não apenas a multiplicação do mesmo é incontornável, como a normalização dos vernáculos se torna uma questão de estandardização profissional. A ortografia, a pontuação e a regularização da morfologia concernem aos impressores tipográficos (com ou

\footnotetext{
12 Scarton (2009, p. 24), tratando dos acordos ortográficos, relata uma "fase de aproximações" somente a partir da década de 60 (1967 - 2013 mais especificamente), nomeando o interstício anterior, que vai de 1904 a 1955 , como "fase dos desacordos". No mesmo tom, veja-se a declaração de Souza e Mariani (1996, p. 91): "A partir de 1971, a questão ortográfica não foi retomada. Parece que continua aberta". O texto original, esclarecem as autoras em nota, foi realizado em novembro de 1985

${ }^{13}$ Kemmler (2015, p. 53) alude a uma "ortografia usual", entendida como uma "norma reconciliadora entre as tendências etimologizante e fonética" que predominava até "finais do século XIX". Encontramos, em publicação anterior do autor, a origem e a validação desse termo (cf. KEMMLER, p. 2001, p. 249-250), empregado e comentado na Grammatica Philosophica (1822), de Soares Barbosa. Sem embargo, preferimos não trabalhar com essa noção, devido não ao termo em si (porquanto a remissão ao uso, via o adjetivo "usual", torna a nomenclatura, em certa medida, inconcussa para exprimir a realidade gráfica do português em sincronias pretéritas) tampouco à sua origem e aplicações novecentistas, mas por razões de outras sortes, a saber: $1^{\circ}$ pela definição aduzida em Kemmler (2015, p. 53) de "norma" (no singular) "reconciliadora", o que pode suscitar uma interpretação desvinculada da ideia de "usos" (no plural) e mais aproximada da acepção de uniformização (totalmente inapropriada para a realidade gráfica do português em sincronias passadas); $2^{\circ}$ por uma série de julgamentos que nos levam a questionar a solidez conceitual da expressão "ortografia usual”, como Viana (1904, p. 2), reportando-se precisamente a essa exata designação, Chaves de Melo (1971, p. 236), questionando a validade de se referir a um "sistema (?)" anterior a 1934, e Gonçalves (2015, p. 100), tratando das várias propostas de caráter sônico publicadas em 1987 em Portugal; $3^{\circ}$ pelas ponderações que Morais de Melo (2018, p. 94-117) alvitra acerca do cruzamento entre educação e a complexa e plural situação dos tratadistas, bem como sobre os multívocos desdobramentos práticos que eventualmente essa interseção pode acarretar.

${ }^{14}$ Ramírez Luengo (2012) ainda assinala que alguns fatores, como o aumento da alfabetização e da escolaridade, bem como a maior disseminação de materiais impressos (livros e textos), também interferem diretamente na passagem "de um estado em que existe uma maior liberdade (sem prejuízo de prestígio) para o uso de distintas soluções gráficas até o momento em que essa permissibilidade vai se reduzindo gradualmente, até sua minimização drástica quando se impõe e se aceita socialmente a fixação de uma norma gráfica unitária na sociedade" (MORAIS DE MELO, 2018, p. 767).
} 
sem o concurso dos autores e dos gramáticos, e mesmo contra eles) ${ }^{15}$, inicialmente no seio de cada ateliê, depois para todos os que trabalham na mesma língua: a difusão do livro impresso impõe, então, a constituição de um espaço ilimitado no qual cada idioma, liberado da variação geográfica, se tornou isótopo.

Tomando como esteio todo o lastro urdido acima, conhecer o "glossário" de Gonzaga Filho, e acerca dele refletir, pode interessar aos linguistas, sobretudo aos que trabalham com a diacronia e a escrita, pois seu léxicon é o desenho próprio de uma ação metaortográfica em curso no mundo lusófono e porque suas soluções gráficas - que se destacam das demais encontradas nos impressos e manuscritos da época por gozarem de uma plataforma de defesa sustentada por um bacharel em Letras na forma das duas seções supracitadas - permitem ao historiador da língua entender melhor os bastidores da estandardização em curso da ortografia da língua portuguesa.

Metodologicamente, num percurso bibliográfico e documental, a apresentação das ideias de Gonzaga Filho que realizaremos neste trabalho será feita por meio de comentários a passagens retiradas dos dois segmentos supracitados, Simples nota, que antecede a redação do romance, e Post-impressum, que a sucede. Analisaremos, dessas seções, algumas proposições etimológicas, fonéticas, prosódicas e sobre harmonia com a escrita de outras línguas que dão forma à expressão metalinguística de feitio (orto)gráfico no despontar do século XX. Teoricamente, por sua vez, seguimos a perspectivas assumida por vários autores de língua espanhola que Morais de Melo (2018) denominou de Escola Hispânica, dentre os quais figuram Sánchez-Prieto Borja (1998), Pensado (1998), Frago Gracia (2002) e Ramírez Luengo (2012). Nos seguintes termos Morais de Melo (2018, p. 752) define o agrupamento:

\begin{abstract}
Denominamos de Escola Hispânica um grupo de pesquisadores de língua espanhola (em sua maioria, da Espanha) que pensaram a língua escrita do passado compartilhando algumas diretivas, que se mostram, ora explícita ora implicitamente (pelos resultados a que se chega nas pesquisas), em quase todos os estudos que se seguem: a de que não há caos na (orto)grafia de sincronias passadas, mas certas tendências gráficas que precisam ser estudas e conhecidas; e a de que a abordagem grafemática deve ser empreendida primeira e primacialmente com atenção ao sistema escrito da língua, que deverá servir de prumo ou contrapeso para qualquer exame de outro nível: fonético-fonológico, morfossintático, lexical, semântico, dentre outros.
\end{abstract}

Nosso artigo está estruturado nos seguintes tópicos: esta introdução, que situa o objeto de estudo no quadro da Grafemática e da história das ideias linguísticas, bem como no seu contexto histórico, justificando, por essa ancoragem, o estudo das duas notas em exame, além de apresentar, mui sumariamente, a via metodológica e a orientação teórica deste trabalho; a seção 1, Anúncio de uma inquietação metaortográfica, em que retratamos o perfil cogitabundo de Gonzaga Filho acerca das questões (orto)gráficas; a parte 2, Na unidade das vozes, o heterogêneo que as une, em que colhemos, na historiografia, vozes com as quais o autor comunga para demonstrar a heterogeneidade na qual a grafia estava imersa; o item 3, Forte on fraco, não era sem base, em que descrevemos as motivações de ordem fonética (tópico 3.1 Motivações fonéticas) - e, de igual modo, as desmotivações que competiam para a escolha gráfica - e de ordem etimológica ligadas, de maneira recorrente, à proposição de uma harmonia com a ortografia de outras línguas - 3.2 Motivações etimológicas e barmonização (neolatina); e a seção 4, Um post-scriptum (quase uma conclusão) possivelpara as simples notas, que são as considerações finais.

\footnotetext{
${ }^{15}$ A discussão sobre a mão última que decidiu pelas formas gráficas é bastante interessante. A sondagem desse punho autoral, porém, é intrincado e labiríntico. Optamos por não adentrar seus umbrais. Para compreendê-lo melhor, indicamos a leitura de Gonçalves e Ferreira (2001), Mattos e Silva (2002), Barbosa e Lima (2019) e Lobo e Carneiro (2019).
} 


\section{Anúncio de uma inquietação metaortográfica}

O perfil bibliográfico de Gonzaga Filho é desvelado na sessão Principaes publicações do mesmo auctor de seu romance $A$ mais encantadora mulher. Do conjunto heterogêneo de seus textos, nossos olhos quedaram-se em dois tipos: 1. seus apontamentos no jornal O Globo: Orgão da Agencia Americana Telegraphica dedicado aos interesses do Commercio, Lavoura e Industria (RJ), cuja presença, curta, mas significativa, nos meses iniciais dos anos de 1882, manteve ativa a seção intitulada Questões de linguistica ${ }^{16} ; 2$. seu romance $A$ mais encantadora mulher - um romance para senhoras, publicado nos idos de 1903. De Questões de linguística, tomemos um excerto para exemplificar o envolvimento de Gonzaga Filho com questões relativas à criação de novas palavras na língua portuguesa, bem como sua repercussão.

(1) ${ }^{17}$ De todas as palavras, porém, que não tenha encontrado nem em diccionarios portuguezes, nem em auctor de nota, uma ha que já tive occasião de empregar, sendo incrivel que não figure em lingua de christãos, onde ha anjo, angelico etc. É o substantivo - angelitude ou angelidade. Reparem na pergunta e resposta seguintes: - o que é que mais te arrebata na madona que vês neste quadro? A angelitude (O GLOBO, 1882, p. 03, grifo do original).

Em edição avulsa, do mesmo ano, o jornal Gažetinha noticia e acende os exercícios e engajamento do escritor com a criação do referido neologismo:

(2) O proponente do necessario neologismo angelitude, que não existe nos diccionarios e bons autores portuguezes, desejando que elle crie raizes, enriquecendo ainda mais a nossa bella lingua, pede-nos que publiquemos o seguinte: [...] Satisfazemos com todo gosto ao pedido do distincto auctor das Questões de linguistica, do Globo, sinceramente magoados por não podermos dar a S.S maior prova de... angelitude (GAZETINHA, 1882, p. 01, grifo do original).

A referência ao neologismo vem à tona, pelo punho do próprio autor, vinte e um anos depois, como registrado n'A Mais encantadora mulher:

(3) Angelitude (por mim, ha annos, proposto) (GONZAGA FILHO, 1903, p. 18).

É sobre o conteúdo retirado das duas notas, Simples nota e Post-impressum, desse romance que trataremos nos tópicos subsequentes.

\section{$2 \mathrm{Na}$ unidade das vozes, o heterogêneo que as une}

Gonzaga Filho, na Simples nota, comungava, em uníssono coro, com tantas vozes que assinalam a anarquia e o desalinho instaurado na escrita do português. Na obra Ortografia nacional - simplificação e uniformização sistemática das ortografias portuguesas, publicada pelo filólogo,

\footnotetext{
16 Os termos em itálico estão grafados conforme se lê em Gonzaga Filho (1903), daí linguistica (sem acento nem trema, caso se esperasse esse diacrítico para o registro da época), Commercio etc.

17 Por se tratar de obra do início do século XX, com muitas peculiaridades gráficas que destoam do padrão ortográfico vigente hoje, optamos por enumerar e recuar em $4 \mathrm{~cm}$ à esquerda todas as passagens transcritas de Gonzaga Filho (1903), independentemente de terem mais ou menos de 3 linhas, no padrão do que fez, a modo de ilustração, Pagotto (2013). Não seguimos, contudo, essa convenção, no caso de Gonzaga Filho, em trechos assaz pequenos (meia linha, por exemplo), nem para as demais obras de séculos passados - como Feijó (1734), Vieira (1871) e Viana (1904) -, de modo que as numerações indiquem apenas excertos com a dimensão de uma linha ou mais do autor em foco.
} 
foneticista e um dos maiores lexicógrafos portugueses do início do século XX, Gonçalves Viana, por exemplo, lemos, imediatamente nas primeiras linhas da obra:

\begin{abstract}
Nunca existiu ortografia uniforme em Portugal: pretender provar o contrário, ou mesmo insistir na afirmativa, seria obstinação ou ignorância manifesta dos factos. Cada escritor tem usado a sua ortografia, mais ou menos metódica, sem entrarem em linha de conta aquelas que são indiscutivelmente erróneas, ou caprichosas, ou irreflectidas (VIANA, 1904, p. V).
\end{abstract}

E já no prefácio da obra, Viana assim declarava: "Este opúsculo não é um tratado de ortografia portuguesa; é antes um inquérito, e a crítica minuciosa, desenvolvida e documentada da actual anarquia ortográfica" (VIANA, 1904, p. V). Esse "inquérito", essa "crítica minuciosa", responde bem à demanda de Gonzaga Filho ao requerer "um lexicon", de suprema, de reconhecida auctoridade" para evitar que cada escritor imponha "a propria opinião" (GOZAGA FILHO, 1903, p. 09).

Em tons menos ásperos e sem a tamanha intensidade de Viana, Vasconcellos (1959), em suas Lições de Filologia Portuguesa, cuja primeira edição data de junho de 1911, faz despontar as seguintes observações ortográficas: "É sabido que cada moderno escritor nosso adopta, por assim dizer, sua ortografia. Isto vem já de longe". Ao que o filólogo acrescenta de imediato que as hesitações naturais da escrita da língua e os entraves vêm justamente do "modêlo tirânico do latim" - ou seja, do modelo etimológico ao qual as línguas românicas estariam submetidas -, resultando de "tais embaraços [...] um mixto na ortografia, não somente na medieval, senão também na dos tempos posteriores" (VASCONCELLOS, 1959, p. 205).

De Carolina Michaëlis Vasconcelos (VASCONCELOS, s.d), extraímos outra referência bem específica, vinda no tópico I de seu texto Ortografia nacional:

\begin{abstract}
Em Portugal não há, nem houve nunca, ortografia oficial, uniforme. Só ortografias variadas, mais ou menos sensatamente regradas pelo costume e exemplo de bons autores, ou mais ou menos inçadas de erros, contradições, dislates, caprichos e idiosincrasias pessoaes. Esse estado pessoal foi tomando proporções de verdadeira calamidade nos últimos decénios do século passado. [...] Houve e ha escritores que na mesma estrofe de um poema, na mesma pájina de uma novela nos apresentam formas híbridas e contraditórias, não reformadas, meio reformadas ou inteiramente reformadas, como mytho e rythmo; melancólico e eccho; aflito e fructo; próximo e próprio; seria (isto é séria) e Maria; quiz e mês; allucinante e captivante; outomnal e insónia. Uma confusão magna (VASCONCELOS, s/d, p. 101).
\end{abstract}

Vasconcelos (s.d.) segue a linha mais contundente de Viana (1904). Da constatação de que havia "ortografias variadas, mais ou menos sensatamente regradas pelo costume e exemplo de bons autores, ou mais ou menos inçadas de erros, contradições, dislates, caprichos e idiossincrasias pessoaes" (VASCONCELOS, s/d, p. 101), chega-se a um "estado pessoal [que] foi tomando proporções de verdadeira calamidade nos últimos decénios do século passado" (Idem). Da dita sensatez à "calamidade magna" pode-se ler, supostamente, que o acesso ao texto escrito e o próprio ato de escrever tenha saído das mãos dos bons escritores para a de escritores menos renomados, ou para outros meios através dos quais a escrita começara a surgir.

\footnotetext{
18 O Dicionário Houaiss registra apenas "léxicon" (proparoxítona), cuja primeira acepção é "m. q. LÉXICO (subst.)" (HOUAISS; VILLAR, 2008, p. 1750). Pelo teor da discussão promovida por Gonzaga Filho (1903) e pela proposta que ele desenvolve nas páginas seguintes de sua Simples nota, podemos afirmar que "lexicon", tal como aparece anotado na edição, possui o significado de "vocabulário", "glossário" (terceira acepção dada pelo dicionário para "léxico").
} 
Afastando-nos desta imagem de caos, podemos afirmar que se trata, na verdade, de um período bem específico, na medida em que convivem tradições gráficas diversas. Essa realidade é, como vemos nos autores acima citados, pintada com adjetivos ou sintagmas que predicam a variação das formas gráficas com conotação negativa: "anarquia ortográfica", "confusão magna", formas "errôneas", "caprichosas", "irreflectidas", "contradições", "dislates", "caprichos", "idiosincrasias pessoaes", "erros", "calamidade”. Essa concepção de caos grassou pelas décadas seguintes e pode ser encontrada em muitos manuais clássicos, e até em obras contemporâneos, de linguística e filologia, conforme podemos conferir em Morais de Melo (2018, p. 64-94). O autor, afora a discussão promovida sobre esse julgamento, alerta para o risco de esse conceito acarretar uma "exclusão sumária [do estudo dos usos gráficos em sincronias passadas] das agendas de estudo por se considerar improdutiva e inviável uma investigação sobre a manifestação de escritas passadas" (Ibidem, p. 64).

Em sua tese, Morais de Melo (2018) investiga textos manuscritos produzidos no Rio Grande do Norte entre 1713 e 1950 e chega à conclusão de que, no lugar de um caos (orto)gráfico $^{19}$, o que se constata é um grande número de tendências que foram se configurando de formas várias e que sedimentaram o caminho de normalização que ganha contornos de uniformidade a partir da segunda metade do século XX. O testemunho de Ramírez Luengo (2012, p. 168-9, tradução nossa) abaixo delineia bem essa situação:

\begin{abstract}
descobrir não apenas a coexistência de diferentes tendências ortográficas entendidas como conjuntos de soluções gráficas aceitas socialmente em um momento concreto - durante a época áurea e mesmo no século XVIII, mas também como a partir desta última centúria parece ocorrer um processo de decantação dessas distintas tendências, de maneira que uma delas vai pouco a pouco adquirindo preponderância e, impondo-se sobre as demais, adquire o caráter de norma ortográfica; este processo histórico - cujas causas são muitas e variadas, e muito provavelmente vão desde o aumento da alfabetização e da escolaridade até a maior difusão dos livros e dos textos impressos na sociedade implica naturalmente uma drástica redução da liberdade existente até o momento no uso das grafias e, consequentemente, a aquisição de certo valor sociolinguístico por parte desta norma ortográfica (RAMÍREZ LUENGO, 2012, p. 168-169, tradução nossa).
\end{abstract}

Não sendo, contudo, o fito deste artigo um controle estatístico dos usos gráficos encontrados em Gonzaga Fillho (1903) - o que poderia levar a um quadro interessantes de possíveis tendências gráficas em um texto impresso das primícias do século XX o qual, somado a materiais congêneres de outros autores da mesma época, geraria um painel revelador das veredas mais seguidas pela língua escrita de então -, veremos a seguir uma página da diacronia pelo prisma das reflexões metaortográficas que o romancista nos legou.

\title{
3 Forte ou fraco, não era sem base
}

$\mathrm{O}$ autor de $A$ mais encantadora mulher não poderia se dar ao luxo de fazer escorrer pela sua pena um glossário contendo todas as formas gráficas que se desenham pelas mais de quatrocentas páginas de seu romance, embora defenda que

\footnotetext{
${ }^{19}$ Frago Gracia (2002, p. 158-159, tradução nossa), pensando em textos que vão do século XVI até o século XIX, afirma que "Em um e outro caso, imprensa e manuscritos, a ausência de uma norma uniforme e efetiva propiciou a variação ortográfica, grandemente propagada das sincronias anteriores, mas jamais houve lugar para caos ortográfico de nenhum tipo, pois do que se tratava era da coexistência de velhas tendências, coincidentes em aspectos fundamentais e divergentes em outros usos, normalmente secundário, algumas das quais incorporavam as inovações que, no transcurso do tempo, iam se produzindo".
} 
(4) por mais corriqueiro, não ha - em todo este romance - vocabulo algum, que deixasse, de ter sido o objecto de especial analyse (GONZAGA FILHO, 1903, p. 18).

E clarifica:

(5) Não posso excessivamente alongar esta simples nota. Si me espraiei mais do que pretendia, foi isso devido a um utopistico anceio, que por ahi vive a sonhar com uma graphica simplificada, quando tão distante nos achamos da infancia da lingua, havendo valiosas conquistas a manter e a aperfeiçoar. Não nos falta um systema, em que brilhem os indifferentes, e sim um diccionario, com força de lei, afugentador de plausiveis discussões, e que nos dê o antegoso de saber, que estamos escrevendo, qual escrevem os doutos (GONZAGA FILHO, 1903, p. 17-18, grifo do original).

Sua escrita "graphica simplificada" respondia pelo anseio de seguir um dicionário que afugentasse a variedade gráfica sem, contudo, olvidar o ensinamento de árduos trabalhos e custoso valor, pois, consoante o autor, há "valiosas conquistas a manter e a aperfeiçoar". Não se trata, assim, de um caos indigente ou de um corpo desinformado, mas de grafias constituídas no e pelo sistema da língua portuguesa. Segundo explana, necessário se faz eleger e normatizar uma delas, movimento que já se estabelecera em outros idiomas:

(6) Complicadissima é a orthographia ingleza, nada facil a dos francezes; entretanto, com os livros de Webster e da Académie Française, qualquer estudioso sente-se no mesmo pé de egualdade do hespanhol, que dispõe, do que andamos impensadamente a namorar (GONZAGA FILHO, 1903, p. 18 , grifo do original).

O inglês dispunha do dicionário An American Dictionary of the English Language, publicado pelo lexicógrafo Noah Webster, nos anos de 1807. Se a ortografia da língua francesa, por sua vez, parecia-lhe difícil, havia o esforço da Academia Francesa, com a publicação oficial de seu Dictionaire de l'Académie, cujas primeiras letras aparecem nos anos 1690, já com o objetivo de normatizar a língua francesa - sendo atualizado até os dias atuais. Do mesmo modo, no mundo hispanófono, buscou-se, imediatamente, impor a implantação de uma norma gráfica de forte aceitação e disseminação, que passa, até hoje, pela imagem da Real Academia Española, a RAE, fundada em Madrid, em 1714. Em Portugal, essa uniformização passaria pelas mãos da Academia das Ciências de Lisboa; no Brasil, pelas futuras missões da Academia Brasileira de Letras, fundada em 1897. E, assim, o gosto pessoal daria lugar a uma padronização elaborada por uma obra lexicográfica de que andava o autor "impensadamente a namorar". Esse namoro flertava com o surgimento de instituições que se ocupassem em uniformizar o sistema ortográfico. Entendemos que o estado gráfico atual, normatizado, não nasceu duma formalização dicionarística, sendo afugentada a dimensão política, social, cultural e linguística. A norma ortográfica atual, antes de um projeto de lei, é um fluxo de natureza e um patrimônio linguístico que faz despontar todas essas dimensões.

A autoridade do Dictionaire de l'Académie, por exemplo, impediria, nas palavras de Gonzaga Filho, que

(7) um francez adopte ou physiognomie, chevallier, anévrysme, etc., ou doner, soufrir, faloir, etc.; não fará eschola, contra o estatuido no Dictionaire de l'Académie, que apenas ensina - physionomie, chevalier, anevrisme, donner, souffrir, falloir, etc. (GONZAGA FILHO, 1903, p. 09, grifo do original).

Sendo outra a situação do português, justifica a marcação de seu "glossário" metaortográfico: 
(8) Em portuguez, porém, não ha, a quem obedecer; e, dahi, mau grado meu, tive, neste pensado livro, de seguir a minha graphica (Idem).

No início do Post-impressum, o autor de $A$ mais encantadora mulher defende que suas escolhas seguiam certos padrões, que não as realizava por capricho, mas estabelecia bases e as seguia de modo coerente:

(9) Disse, na Simples nota, que, forte ou fraco, nao era sem base, que eu anteporia uma fórma a uma outra, adduzindo, entao, varios exemplos expressivos. Deverei, agora, multiplical-os, depois que o leitor, de posse da minha graphica, provavelmente verificou a coherencia, que mantive, da primeira pagina até a ultima? Si não o creio, parece-me de prudencia, que, ao menos sobre meia duzia de irrequietas questiunculas, com toda a franqueza me explique (GONZAGA FILHO, 1903, p. 431, grifo do original).

Efetivamente não eram sem base, senão de base vária: etimológica, fonética, de harmonização (neolatina), em usos já estabelecidos e socialmente aceitos expostos em documentos de toda sorte (jornais, cartas, livros de grandes escritores). Também não faltou, nesse alicerce, a força imperativa de um panteão dicionarístico citado na Simples nota, do qual levantamos uma pequena descrição: $1^{\circ}$ Antônio Morais Silva (1975-1824), responsável por reformar o Diccionario da Lingua Portugueza, de composição original do padre D. Rafael Bluteau ${ }^{20} ; 2^{\circ}$ Francisco José Freire (1719-1773), que, sob o nome de Cândido Lusitano, publicou, em dois volumes, nos anos de 1765, o Diccionario poetico, para uso dos que principião a exercitar-se na poesia portugueza: obra igualmente util ao orador principiante; $3^{\circ}$ Francisco Júlio Caldas Aulete (1823-1878), que iniciou um projeto de publicação, em 1881, do Diccionario Contemporaneo da Lingua Portugueza; $4^{\circ}$ Frei Domingos Vieira, autor do Grande Diccionario do Portuguez, on Thesouro da Lingua Portugueza, publicado em 1871.

\subsection{Motivações fonéticas}

Sabendo-se da formação em Letras de Gonzaga Filho, não é de se espantar seu domínio científico sobre a nomeação dos metaplasmos ocorridos nas palavras. Termos como aférese, degeneração, eufonia, geminação, assimilação, síncope, apócope e prótese são recorrentes no estabelecimento de suas bases. Elegemos somente aqueles que mais receberam atenção intensa do escritor, isto é, para as quais reservou mais espaço.

Luzem, assim, regras de movimentos fonéticos sofridos pelos sons da língua portuguesa no decorrer da história. Eis que o autor desfila seu conhecimento linguístico sobre regras fonéticas, conforme vemos bem defendidas na forma como prefere grafar o termo "afastar" (em vez de "abstare"):

(10) Afastar - Com um só $f$, por me parecer palavra popular. A etymologia (Moraes) abstare fere a regra, de que $b$ latino não degenerou em $f$ (GONZAGA FILHO, 1903 , p. 10 , grifo do original).

Tamanha atenção ao fenômeno da degeneração conduz-nos ao destaque dado por ele à eleição gráfica da palavra "asa", quando alguns dicionários davam preferência à grafia "aza".

(11) Asa - Não poderia provir de alam; o l medial ou é resistente (taleam, tala; militiam, milicia) ou syncopa-se (aquilam, águia, palum, pau); ou degererase em

\footnotetext{
${ }^{20}$ Foi o primeiro dicionário organizado por um estudioso brasileiro e teve sua primeira edição publicada nos idos de 1789. Para Verdelho (2003), é a mais importante obra de referência na história da lexicografia de língua portuguesa.
} 
$r$ (lilium, lirio.; cumulum, comoro). Degeneração em z (como querem os grafistas de aza), é tudo, que ha de problematico. De alam, ala, alar; de modo nenhum asa, que prende-se a ansam. Também ficou em evidencia, o porque escrevo aso, o verbo asar, asado, asadamente. Com z, az (carta de jogar) e azar (acaso, sorte), de arabica origem (GONZAGA FILHO, 1903, p. 11, grifo do original).

De fato, Moraes Silva (1789) e Vieira (1871), por exemplo, preferem a notação “aza”. No Diccionario do Portuguez ou Thesouro da Lingua Portugueza (VIEIRA, 1871, p. 687, grifo do original), encontramos esta referência: "Do latim ala, segundo o Diccionario da Academia; melhor, do latim axilla, abreviando-se em axla, que no francez antigo se dizia aisle, syncopando-se o «1» segundo a índole da lingua portugueza". Vieira e Morais seguem de perto o Diccionario da Lingoa Portugueza (1793), publicado pela Academia Real das Ciências. Mas Gonzaga Filho desconsidera essa relação direta com a palavra "axilla". Para ele, "asa" provém de "ansa", após síncope do som " $n$ ". A forma com " $z$ " originária do latim "alam" é descartada pelo autor, já que, de acordo com sua explicação, se, por um lado, certas formas gráficas demonstram como o "l" medial é resistente à degeneração (como em militiam $>$ milicia), sincopa-se (a exemplo de aquilam>águia) e sofre degeneração em " $r$ " (lilium>lírio), por outro, considerar que "l" se degenera em " $\mathrm{z}$ " é descabido, é "tudo, que ha de problematico".

O autor, em outra situação, mostra sua predileção pela escrita de certas palavras com " $z$ ", como destacado no excerto:

(12) Accompanho, os que com z fecham terminações longas: ananaz, rapaz, elle traz, intrepidez, francez, portuguez, elle fez, matiz, feliz, liz (flor de), eu fiz, retroz, foz, elle poz, cruz, luz, andaluz, eu puz, elle produz, etc. Exceptuo: fas (por fas ou nefas), aliás, assás, trás, atrás, detrás, has, tu dás, tu estás, as segundas do futuro tu serás, amarás, ferirás, venderás, porás, através, Moysés, revés, tu dês, tu vês, tu lês, três, gurupés, após, cós, flos, vós, nós, obus, pus, jus, Jesus, vis, tris, flux e sus. Com ter seguido tal regra, que me levou ás graphias paiz, portuguez, Pariz, francez, etc., não se conclue, que, nos vocabulos derivados, me esqueça de restabelecer, o que mais consentaneo é com a etymologia, pois escrevo: paisagem, aportuguesar, parisiense, francesismo, etc., cumprindo-me explicar, que, devido a essa dicta regra, escrevendo eu marquez, e dahi marqueza, conformei-me ao uso geral nas graphias princeza, baroneza, duqueza, prioreza, alteza, embora saiba, que com $s$ é o correcto (GONZAGA FILHO, 1903, p. 15-16).

Pela corrente da "má pronunciação"21, o autor faz uma predileção gráfica pela escrita de "involver" com "i".

(13) De involvere fez a prolação portugueza involver. Quem diz envolver, será capaz de pronunciar envento, enteresse (GONZAGA FILHO, 1903, p. 11, grifo do original).

O autor também busca critérios pelo caminho da harmonia fônica, afirmando, nessa questão, sua aproximação (ou gosto pessoal) a autores que também haviam decidido por ela.

\footnotetext{
${ }^{21}$ Gonzaga Filho estabelece um prognóstico muito semelhante àquele encontrado em Feijó (1734) que, já no século XVIII, publica o manual, de grande sucesso por um longo período, Orthographia; ou, Arte de escrever: $e$ pronunciar com acerto a lingua portugueza para uso do excellentissimo duque de Lafoens, no qual se encontra compilado o que o ortógrafo setecentista considera erros de pronúncia. A esse respeito, lemos a seguinte passagem, com que o autor abre a terceira parte da referida obra: "Se o vulgo indouto naõ errara a recta pronunciação de innumeraveis palavras, seria facil ensisarmos a todos a escreve com acerto" (FEIJÓ, 1734, p. 143).
} 
(14) - Olympio (olympico), etc., etc. Preferindo (antes de um que) olympio (lat. Olympium) a olympico (lat. olympicum), José de Alencar, cujo delicado ouvido tanto se pareceu com o de Francisco Octaviano e o de Almeida Garrett, disse muito bem: "A harmonia é uma das primeiras bellezas da língua". Desgosta, aos que buscam algo mais, do que eslagartar a syntaxe, reconhecerem a sem razão, com que os dicionários restringem os recursos do nosso opulento idioma, ora obsoletando uteis palavras (ternal, por exemplo, o mesmo que ternario, e que perfeitamente se ajeitará com a parentela dual, decimal, vigesimal, etc.), e ora nem fazendo menção de consagradas variantes (gradil para prova, e que está para grade, qual covil para cova, hastil para haste, etc). Vê-se, pois, que os meus esforços se não reduziram apenas á graphica, e que tambem se extenderam ao farto vocabulario, de que se compõe este livro (GONZAGA FILHO, 1903, p. 22, grifo do original).

Mas, na maioria dos casos, a preleção pela pronúncia vinha, quase sempre, acompanhada de uma explicitação etimológica, seguindo de perto os passos das línguas românicas. Assim diz Gonzaga Filho sobre a pronúncia da palavra "sorrir":

(15) Surrir, surriso - A etymologia surridere deu a primeira licção, e a portugueza prosodia repetiu-a, desde que approximou taes vocabulos do fr. sourire. Fala mal, quem diz sôrrir, em vez de surrir (GONZAGA FILHO, 1903, p. 10, grifo do original).

\subsection{Motivações etimológicas e harmonização (neolatina)}

A afeição etimológica - que para Gonzaga Filho já lhe foi, outrora, seu "querido estandarte" - mantém-se, mas de forma ambígua. Ora é preservada, ora é deixada de lado. No segundo caso, isso acontece quando a grafia das palavras já se convertera "no mais generalizado uso". É uma forma sensata de se defender por não seguir os caminhos da etimologia:

(16) Superficial exame classificar-me-ha entre os etymologistas. De feito, o sou; e já fui intransigente, que pugnava por charta, chorda, mactar, mês, português, París, chirurgia, etc., contra o que se converteu no mais generalizado uso, isto é, carta, corda, matar, mez, portuguez, Pariz, cirurgia, etc. Sem embargo, si aqui ainda empunho o antigo e querido estandarte, busquei fugir á pecha de exquisitão, passando a acceitar algumas dessas defeituosas formas. Lancem, pois, os benevolos leitores á conta de tal tolerancia quaesquer apparentes cincadas, e creiam que, forte ou fraca, não é sem base que anteponho uma grafia a outra (GONZAGA FILHO, 1903, p. 09, grifo do original).

Com essas palavras observamos como, ainda que a etimologia parecesse um caminho acertado, nem mesmo Gonzaga Filho poderia ir "contra o que se converteu no mais generalizado uso", aceitando o que ainda lhe pareciam "defeituosas formas". A escrita de palavras como "carta", "corda" e "cirurgia" ganhara, assim, força frente a "charta", "chorda" e "chirurgia".

$\mathrm{O}$ autor encontra ainda um modo bem específico de empunhar "o antigo e querido estandarte". É nesse momento que o autor faz uso de uma proposição muito particular, que ele nomeia de harmonia neolatina. Foi assim que decidiu pela grafia da palavra "Brasil" e "brasileiro".

(17) Brasil, brasileiro - Formigam estirados artigos em favor de $s$, e também de ₹ que é pura graphia ingleza. Mas o bom-senso litterario nos está bradando, a não quebrarmos a harmonia neo-latina: escreveram, escrevem e escreverão Brésil o francez, Brasile o italiano, e Brasil o hespanhol (GONZAGA FILHO, 1903, 11, grifo do original). 
Por esse motivo, o escritor lança mão de uma filiação etimológica no que concerne às línguas latinas. Tomando como exemplo a palavra "Brasil" em detrimento de "Brazil", o autor assume que a presença da letra " $z$ " é "pura graphia inglesa" e adere a uma "harmonia neo-latina", adotando o "s" empregado pelo francês, italiano e espanhol, que grafam, respectivamente, "Brésill", "Brasile" e "Brasil" para o nome do país.

A fundação de algumas de suas soluções gráficas efetivamente passa pelo crivo da harmonia, mas não apenas com formas advindas da ortografia de línguas neolatinas. A pluralidade de referências - que ultrapassam, por vezes, os lindes das línguas românica resulta, amiúde, no verdadeiro peso. É por essa rota que emprega "accompanhar" com "c" geminado, pois se tem uso parelho em três idiomas (dos quais apenas dois são românicos, sendo o terceiro, note-se, o inglês, que já fora rechaçado como molde para outras grafias, a exemplo de "Brazil" com " $z$ ").

(18) Accompanhar - Obscura e controvertida é a origem; mas o mesmo se dá para o fr. accompagner, it. accompagnare, ing. to accompagny (Ibidem, p. 9, grifo do original).

Nesse expediente, deixa de lado a simplificação verificada no espanhol (“acompañar"), em cujo sistema gráfico se fixaram, via de regra, apenas as geminadas que possuem transcendência fônica. Três contra um, ganham o francês, o italiano e o inglêes ${ }^{22}$.

(19) Ora, nao devendo guiar-me pela simplicidade castellana, que só geminou lettras que teem prosodico valor, não desprezei a licção daquelles tres idiomas (GONZAGA FILHO, 1903, p. 10). com " $y$ "23:

Lição que se estende a outras palavras, a exemplo de "brilho" escrito com “i”, e não

(20) Quanto a brilho, brilhar, brilhatura (it. Billatura), não discuto a etymologia berylium, curvo-me ao uso, que não foi apenas despotico em portuguez, mas tambem no francez, castelhano, italiano e inglez (Ibidem, p. 13, grifo do original).

A justificativa pela harmonia ganha seu ponto mais alto no momento de grafar a palavra "lettra", para a qual dedica a seguinte justificativa:

(21) Lettra - Vindo, alphabeticamente, lite antes de litt, clarissimo, que os melhores lexicons, ao chegarem a littera, mandem ver, o que já foi definido, isto é, litera. Indubitavel, porém, que, em optimo latim, campeam ambas as graphias; e, dahi, mesmo para os etymologistas, facultativo será, escreverem lettra, ou letra. Os hespanhoes nao desgostam da chocarrice, de que o portuguez nao passa de "castellano mal hablado", e para que não venham a salgal-a de "y mal escrito", não desprezemos occasiões de exercitar bom-senso litterario. Esse vertente caso não parece dos peiores: optando pela graphia latina littera, nao desafiaremos a natural surpresa do francez lettre, do italiano lettera, do inglez letter, e do allemão letter. De minha parte, escrevo e escreverei - lettra, litterario, litteral, litteratura, solettrar, etc., com $t$ (Ibidem, p. 431-432, grifo do original).

\footnotetext{
${ }^{22} \mathrm{O}$ espanhol, não obstante, dita a forma em outras palavras que, segundo o autor, têm nele seu berço: “Estallar, solluçar, callar (não falar) - Para aviso, de que são vocabulos castelhanos, grapho-os com $l l$, aportuguesando-os na prosodia" (GONZAGA FILHO, 1903, p. 10, grifo do original).

${ }^{23}$ Com "y" ele escreve o substantivo "giro" e "girar", como decalque do modelo clássico: "Gyro, gyrar Respeitando essa graphia grega e latina (porque escrevo lyceu, gymnasio, etc.), evito a contradicção, em que cahiu Aulete, com giro e gyroscopio" (Ibidem, p. 13, grifo do original).
} 
Nota-se acima que - sendo, mesmo aos etimologistas, facultadas duas formas Gonzaga Filho opta pela geminada no encalço dessa afinação que, como afirmamos acima, é regida prioritariamente pela quantidade de modelos disponíveis, pois, uma vez mais, extrapola-se o conjunto das línguas românicas. Destarte, o espanhol é deixado novamente à parte, e une-se o autor aos exemplos não só do francês (lettre) e italiano(lettera), mas também de duas línguas germânicas, o inglês (letter) e o alemão (letter), para escrever em seu romance "lettra" e outras palavras construídas sob o mesmo étimo: "litterario, litteral, litteratura, solettrar".

\section{Um post-scriptum (quase uma conclusão) possível para as simples notas}

Finalizamos o presente estudo com as últimas palavras da Simples nota, que parecem evidenciar como, tal qual se dá neste trabalho, esgotar o tópico - na extensão/construção de um léxico próprio para sua obra, no caso de Gonzaga Filho; na devassa exaustiva de todos e cada um dos léxicos por ele postos na ribalta, em nosso caso - não era sua intenção:

(22) E fecharei esta Simples nota, porque si, em vez de distracções com a leitura de um decente romance, o leitor carecer de se entregar a um escudo raciocinado, segundo os principios hodiernos da sciencia da linguagem, encontrará na Grammatica Portugueza, do habil professor José Ventura Boscoli, um trabalho completo, e que já teve a consagração dos competentes (GONZAGA FILHO, 1903, p. 22, grifo do original).

Observamos que, no discurso metaortográfico defendido nas duas seções em fito situadas às margens de seu romance, é a afeição etimológica a que brada mais forte, especialmente se incluirmos nessa esfera a harmonização com as formas escritas em outros idiomas. Algumas soluções, contudo, respondem ao mais generalizado uso, engendrando figurações gráficas que escapam aos padrões etimológicos.

Encontramos, no livro de Gonzaga Filho, exemplos de toda sorte e motivações as mais intrigantes que merecem, do historiador da língua portuguesa, atenção cautelosa. A obra em estudo, é, ao fim e à medida, um importante documento sobre a história da (orto)grafia e merece devida atenção, dado o modo como o autor enfrenta a escrita de um léxico ainda não normatizado, deixando transparecer um gosto pessoal que está sempre atravessado pelo discurso metalinguístico: quando o autor escolhe suas formas prediletas, no seio de uma configuração gráfica ou outra, busca um amparo de ordem técnica, seja de que natureza sua motivação possa ser.

No intento de saciar sua sofreguidão por um dicionário com força de lei, o autor acabou buscando as suas próprias leis - analógicas, fonéticas, etimológicas... Perscrutamos algumas delas. E A Mais Encantadora Mulher permanece chão fértil para outras aventuras historiográficas.

\section{REFERÊNCIAS BIBLIOGRÁFICAS}

ASSALIM, Clarice. A conservação de marcas gramaticais arcaicas em manuscritos e impressos do português do século XVII: ortografia e nexos de coordenação nos textos seiscentistas brasileiros. v. 1. 2007. 194f. Tese (Doutorado em Filologia e Língua Portuguesa). Universidade de São Paulo, São Paulo, 2007.

AUROUX, Sylvain. A revolução tecnológica da gramatização. Campinas, SP: Editora da Unicamp, 2009. 
BARBOSA, Afranio Gonçalves; LIMA, Alexandre Xavier. O controle indireto de perfis sócio-históricos em corpora histórico-diacrônicos: a indentificação de graus de letramento pela grafia etimológica do século XIX. In: CASTILHO, Ataliba Teixeira de (Org.). História do português brasileiro: corpus diacrônico do português brasileiro. São Paulo: Contexto, 2019.

BLECUA, José Manuel; GUTIÉRREZ, Juan; SALA, Lidia (Orgs.). Estudios de grafemática en el dominio hispánico. Bogotá: Ediciones Universidad Salamanca; Instituto Caro y Cuervo, 1998.

CATACH, Nina. Les délires de l'orthographe. Paris: Plon, 1989.

CHAVES DE MELO, Gladstone. Iniciação à Filologia e à Lingüística Portuguesa. Rio de Janeiro: Livraria Acadêmica, 1971.

CONTRERAS, Lidia. Ortografía y grafemática. Madrid: Visor, 1994.

ELIZAINCÍN, Adolfo; MALCOURI, Marisa; COLL, Magdalena. Grafemática Histórica: seseo y yeísmo en el Río de la Plata. In: BLECUA, José Manuel; GUTIÉRREZ, Juan; SALA, Lidia (Orgs.). Estudios de grafemática en el dominio hispánico. Bogotá: Ediciones Universidad Salamanca; Instituto Caro y Cuervo, 1998.

FACHIN, Phablo Roberto Marchis. Práticas de escrita setecentistas em manuscritos da administração colonial em circulação pública no Brasil. 2011. 430f. Tese (Doutorado em Filologia e Língua Portuguesa). Universidade de São Paulo, São Paulo, 2011.

FEIJÓ, João de Moraes Madureira. Orthographia, ou Arte de escrever, e pronunciar com acerto a Lingua Portugueza. Lisboa: Officina de Miguel Rodrigues, 1734.

FRAGO GRACIA, Juan Antonio. Textos y normas: comentarios lingüísticos. Madrid: Gredos, 2002.

GAZETINHA. Publicação diária. Número avulso, Ano I, no 31.1882. http://memoria.bn.br/DocReader/Hotpage/HotpageBN.aspx?bib $=706850 \& p a g f i s=433 \&$ url=http://memoria.bn.br/docreader\#. Acesso em 23.02.2020.

GONÇALVES, Maria Filomena. As ideias ortográficas em Portugal. De Madureira Feijó a Gonçalves Viana (1734-1911), Lisboa: Fundação Calouste Gulbenkian/Fundação para a Ciência e a Tecnologia, 2003.

GONÇALVES, Filomena. Ortografia e ideologia: a geração sônica. In: SILVA, Maurício (Org.). Ortografia da língua portuguesa: história, discurso e representação. São Paulo: Contexto, 2015.

GONÇALVES, Uilton dos Santos; FERREIRA, Permínio Souza. Aventura no reino das traças: contribuindo para uma história lingüística da Bahia. In: MATTOS E SILVA, Rosa Virgínia (Org.). Para a história do português brasileiro. Vol. II: Primeiros estudos. Tomo II. São Paulo: Humanitas/FAPESP, 2001.

GONZAGA FILHO, José Basileu Neves. A mais encantadora mulher - um romance para senhoras. Lisboa: Officinas Typographicas da Companhia “A Editora”, 1903. 
GUIMARÃES, Eduardo. Sinopse dos estudos do português no Brasil: a gramatização brasileira. In: GUIMARÃES, Eduardo; ORLANDI, Eni Puccinelli (Orgs.). Língua e cidadania: o português no Brasil. Campinas, SP: Pontes, 1996.

HORA, Dermeval da; BATTISTA, Elisa; MONARETTO, Valéria Oliveira (Orgs.). História do português brasileiro: mudança fonética do português brasileiro. São Paulo: Contexto, 2019.

HOUAISS, Antônio; VILLAR, Mauro de Salles. Grande Dicionário Houais da Língua Portuguesa. Rio de Janeiro: Objetiva, 2008.

KEMMLER, Rolf. Para uma história da ortografia portuguesa: o texto metaortográfico e a sua periodização do século XVI até à reforma ortográfica de 1911. Lusorama: Revista de Estudos sobre os Países de Língua Portuguesa. Portugal: Instituto Camões, n. 47-48, p. 130319, Out., 2001.

KEMMLER, Rolf. Para a história da ortografia simplificada. In: SILVA, Maurício (Org.). Ortografia da língua portuguesa: história, discurso e representação. São Paulo: Contexto, 2015.

LOBO, Tânia; CARNEIRO, Zenaide Novais. Reflexões sobre a constituição e análise de corpora linguísticos históricos e sobre a identificação de perfis sociais de redatores do passado. In: CASTILHO, Ataliba Teixeira de (Org.). História do português brasileiro: corpus diacrônico do português brasileiro. São Paulo: Contexto, 2019.

MASSINI-CAGLIARI, Massini; CAGLIARI, Luiz Carlos. Diante das letras: a escrita na alfabetização. Campinas: Mercado das Letras: Associação de Leitura do Brasil; São Paulo: Fapesp, 2001.

MATTOS E SILVA, Rosa Virgínia. Reflexões e questionamentos sobre a constituição de corpora para o Projeto Para história do português brasileiro. In: DUARTE, Maria Eugênia Lamoglia; CALLOU, Dinah (Orgs.). Para a história do português brasileiro: notícias de corpora e outros estudos. v. 4. Rio de Janeiro: FAPERJ, 2002.

MONTE, Vanessa Martins do. Documentos setecentistas: edição semidiplomática e tratamento das sibilantes. 2007. 395f. Dissertação (Mestrado em Filologia e Língua Portuguesa). Universidade de São Paulo, São Paulo, 2007.

MORAES SILVA, António de. Diccionario da Lingua Portugueza. Lisboa: Typographia Lacerdina, 1789.

MORAIS DE MELO, Felipe. Nas trilhas da escrita: reedição e análise grafemática das cartas oficiais norte-rio-grandenses (1713-1950). 2018. 961f. Tese (Doutorado) - Programa de Pós-graduação em Estudos da Linguagem, Universidade Federal do Rio Grande do Norte, Natal, 2018.

MORREALE, Margherite. La (orto)grafía como tropiezo. In: BLECUA, José Manuel; GUTIÉRREZ, Juan; SALA, Lidia (Orgs.). Estudios de grafemática en el dominio hispánico. Bogotá: Ediciones Universidad Salamanca; Instituto Caro y Cuervo, 1998. 
O GLOBO: Orgão de Agencia Americana Telegraphica dedicado aos interesses do Commercio, Lavoura e Industria. Ilustrado. Publicação diária. Sexta-feira, 3 de fevereiro de 1882. http:/ / memoria.bn.br/docreader/DocReader.aspx?bib $=369381 \& p a g f i s=5410$

PAGOTTO, Emilio Gozze. Gramatização e normatização: entre o discurso polêmico e o científico. In: ORLANDI, Eni Puccinelli (Org.). História das idéias lingüísticas: construção do saber metalingüístico e constituição da língua nacional. Campinas, SP: Pontes; Cáceres, MT: Unemat Editora, 2001.

PAGOTTO, Emilio Gozze. A norma das constituições e a constituição da norma no século XIX. Revista LETRA. Rio de Janeiro, ano VIII, v. 1 e 2, p. 31-50, 2013.

PENSADO, Carmen. Sobre los límites de la mala ortografía en romance ¿Por qué el inglés fish no se escribe ghoti después de todo? In: BLECUA, José Manuel; GUTIÉRREZ, Juan; SALA, Lidia (Orgs.). Estudios de grafemática en el dominio hispánico. Bogotá: Ediciones Universidad Salamanca; Instituto Caro y Cuervo, 1998.

RAMÍREZ LUENGO, José Luis. Notas sobre las tendencias gráficas del español colombiano en la época de las Independencias (1830), J. L. Ramírez Luengo (Org.). Por sendas ignoradas. Estudios sobre el español del siglo XIX. Lugo, Axac, 2012, pags. 167182.

RAMÍREZ LUENGO, José Luis. Algunas notas sobre los usos gráficos del español escrito en Bolivia en los inicios del siglo XIX. Boletín de la Real Academia Española, Tomo XCV, Cuaderno CCCXII, jul./dic. 2015.

SÁNCHEZ-PRIETO BORJA, Pedro. Cómo editar los textoz medievales: criterios para su presentación gráfica. Madrid: Arco/Libros, 1998.

SCARTON, Gilberto. A orthographia da lingoa portugueza, que virou ortografia: História dos desacordos. In: MOREIRA, Maria Eunice; SMITH, Marisa Magnus; BOCCHESE, Jocelyne da Cunha (Orgs.). Novo acordo ortográfico da língua portuguesa: questões para além da escrita. Porto Alegre: EDIPURS, 2009.

SILVA, Maurício (Org.). Ortografia da língua portuguesa: história, discurso e representação. São Paulo: Contexto, 2015.

SOUZA, Tania Conceição Clemente de; MARIANI, Bethania Sampaio Corrêa. Reformas ortográficas ou acordos políticos? In: ORLANDI, Eni Puccinelli (Org.). História das idéias lingüísticas: construção do saber metalingüístico e constituição da língua nacional. Campinas, SP: Pontes; Cáceres, MT: Unemat Editora, 2001.

TONIOLO, Ênnio José. Manuscritos da Vila Nova de Castro: um estudo filológico de documentos dos séculos XVIII e XIX. 2007. 433f. Tese (Doutorado em Estudos da Linguagem). Universidade Estadual de Londrina, Londrina, 2007.

TELLES, Célia Marques. Grafia de textos e fonologia do português nos séculos XV e XVI. Revista ANPOLL. n. 18, p. 43-58, jan./jun., 2005.

TELLES, Célia Marques. Textos escritos por mãos inábeis, sua importância para o estudo da fonologia. Caleidoscópio. São Leopoldo (RS), v. 6, n. 1, p. 28-36, jan./abr., 2008. 
TELLES, Célia Marques; SOUZA, Risonete Batista de. Marcas pontuacionais nos livros do tombo do Mosteiro de São Bento da Bahia. Revista da ABRALIN. v. 14, n. 1, p. 93-128, jan./abr., 2017.

TELLES, Célia Marques. Representação das vogais pretônicas nos Livros do Tombo. In: HORA, Dermeval da; BATTISTA, Elisa; MONARETTO, Valéria Oliveira (Orgs.). História do português brasileiro: mudança fonética do português brasileiro. São Paulo: Contexto, 2019.

VASCONCELLOS, José Leite de. Lições de Filologia Portuguesa. Rio de Janeiro: Livros de Portugal, 1959.

VASCONCELOS, Carolina Michaëlis de Vasconcelos. Lições de Filologia Portuguesa: segundo as preleções feitas aos cursos de 1911/12 e de 1912/13 seguidas das Lições Práticas de Português Arcaico. Lisboa: Martins Fontes, s/d.

VERDELHO, Telmo. O dicionário de Morais Silva e o início da lexicografia moderna. História da língua e história da gramática - actas do encontro. Braga: Universidade do Minho/ILCH, 2003. p. 473-490.

VIANA, Aniceto dos Reis Gonçalves. Ortografia nacional: simplificação e uniformização sistemática das ortografias portuguesas. Lisboa: Viúva Tavares Cardoso, 1904.

VIEIRA, Frei Domingos. Grande diccionario portuguez ou Thesouro da lingua portugueza. Porto, Portugal: Ernesto Chardron, Editor, Porto, Portugal: Bartolomeu H. de Moraes, 1871. 